ORIGINAL ARTICLE

\title{
An audit of clinical practice in the management of head injured patients following the introduction of the Scottish Intercollegiate Guidelines Network (SIGN) recommendations
}

\author{
J Kerr, R Smith, S Gray, D Beard, C E Robertson
}

Emerg Med J 2005;22:850-854. doi: 10.1136/emj.2004.022673

A prospective study was conducted by the Scottish Trauma Audit Group (STAG) in A\&E of Edinburgh Royal Infirmary to examine clinical practices in the management of head injured patients pre- and postinception of the SIGN guidelines published in August 2000.

1607 patients attended the department in two separate one month periods at equal intervals pre- and post-guidelines publication. The majority of patients with a SIGN indication for admission were admitted (93\% pre- and $92 \%$ post-guidelines). For skull $x$ ray (SXR) requests, in the pre-guidelines group, $92 \%$ of

See end of article for authors' affiliations

Correspondence to: Jacques Kerr, Flat 11, 30 B Chambers Street,

Edinburgh, EHl $1 \mathrm{HU}$ United Kingdom; jaxkerr@ freeuk.com

Accepted for publication 24 March 2005 admitted patients with a SIGN indication for $x$ ray had a SXR: this figure dropped to $79 \%$ post-guidelines. $36 \%$ of patients with a SIGN indication for CT actually had a scan pre-guidelines: this figure increased to $64 \%$ post-guidelines.

$57 \%$ of patients pre-guidelines and $44 \%$ of patients post-guidelines were discharged from A\&E in accordance with the SIGN recommendations. Of patients admitted for neurological observations, this increased from $50 \%$ pre- to $88 \%$ post-guidelines. Of patients who were discharged "inappropriately", only one re-presented and was subsequently admitted but required no neurosurgical intervention.

Despite publication of the SIGN guidelines and positive reinforcement in A\&E and at ward level, practice has not changed significantly. Where our practice did not adhere to SIGN recommendations, there was no untoward sequelae. For published national guidelines to be effective, a formal audit structure with regular feedback is necessary to ensure a continued change in clinical practices.

$\mathrm{T}$ rauma is the leading cause of death under the age of 45 years and up to $50 \%$ of deaths are because of a head injury. ${ }^{1}$ About 100000 people attend hospital every year in Scotland with a head injury, and approximately $20 \%$ are admitted. ${ }^{2}$ Of the attendances, the majority (93\%) are Glasgow Coma Score (GCS) 15 on presentation, whereas only $1 \%$ have a GCS of 8 or less. ${ }^{4}$ Nevertheless, head injuries account for a significant proportion of Accident and Emergency (A\&E) workload, and are responsible for a high percentage of the cost of all admissions to hospital. ${ }^{5}$ Patients who sustain intracranial events as a consequence of head injury may suffer long term sequelae if definitive treatment is delayed. Additionally, although figures vary, up to half of all head injured adults may experience long term disability ${ }^{6}{ }^{7}$ It is therefore important that guidelines, based on peer review published evidence, are followed to achieve optimal care.

Guidelines for the management of this group of patients were first endorsed by the Department of Health in $1983^{\circ}$ and since then, with the increase in trauma services and availability of computed tomography (CT) scanning resources, further guidelines, which take these changes into account, have been produced. Initially, the Harrogate guidelines ${ }^{9}$ published in 1984 made suggestions on the early management of head injured patients; this was superseded in 1999 by the Galasko report from the Royal College of Surgeons. ${ }^{10}$ Since then, the Scottish Intercollegiate Guidelines Network (SIGN) published Early Management of Patients with a Head Injury in August 2000. ${ }^{4}$ Perhaps the most contentious aspect of management remains that of radiological assessment; in Scotland, skull radiography is still used as a screening tool, whereas Steill $e t$ al $^{11}$ emphasise the early use of CT scanning. Similarly, the National Institute for Health and Clinical Excellence (NICE) guidelines, ${ }^{12}$ published in 2003, emphasise the use of CT scanning as the primary method of imaging patients with head injury. Despite guidelines, the management of head injured patients in the A\&E has been governed largely by local practice and availability of resources and is therefore inconsistent nationally and internationally. ${ }^{13}$

A clinical audit was conducted to see how our approach changed pre- and post-inception of the SIGN guidelines. This formed part of a national study to examine pre- and postimplementation clinical practices throughout Scotland.

\section{PATIENTS AND METHODS}

The study looked at patients attending the A\&E department of the Royal Infirmary of Edinburgh (RIE) who presented with a head injury. All patients who had sustained blunt force trauma above the neck were included in the study. This included patients with facial injuries. The latter population were included because of the possibility of potential intracranial sequelae. Patients who had sustained a head injury as a result of collapse, and other "medical" conditions, were included, but their subsequent in-patient management was not audited. All other patients were followed to the point of discharge.

Abbreviations: A\&E, Accident and Emergency; $C T$, computed tomography; GCS, Glasgow Coma Score; NICE, National Institute for Health and Clinical Excellence; RIE, Royal Infirmary of Edinburgh; SIGN, Scottish Intercollegiate Guidelines Network; STAG, Scottish Trauma Audit Group; SXR, skull $x$ ray; WGH, Western General Hospital 
The neurosurgical unit that serves Edinburgh and Lothian is based at the Western General Hospital (WGH), remote from the RIE. Patients who required neurosurgical intervention were followed up after transfer to the WGH until final discharge.

The study analysed two separate periods of admissions: 130 November 1999 (period 1) and 1-31 May 2001(period 2). These periods were used for two reasons: first, each represented the fourth month in a standard six month junior doctor post (either February to July, or August to January) and would therefore represent a similar point in the experience level of the assessing doctors; second, each period was precisely nine months pre and nine months post the introduction of the August 2000 SIGN recommendations. As part of their induction programme, all senior house officers are given a one hour tutorial on the management of head injured patients. Since August 2000, this tutorial has been based on the SIGN guidelines; additionally, the guidelines were made available to nursing and medical staff working in the acute wards that have responsibility for the management of head injuries. This involved teaching sessions, posters, and action cards, which contained information on the radiological and discharge criteria for this group of patients. For each patient attending the A\&E department with a head injury, a proforma was completed (see Appendix). Information was collected on the patient's age, sex, details of injury, and clinical presentation. During the attendance, information was also collected on their radiological assessment and its clinical indications. Details were recorded about admission or discharge, and whether this complied with SIGN recommendations, the clinical course during admission, and whether the criteria were fulfilled for safe discharge. For patients transferred to another hospital, data were collected on the indications for transfer, including GCS, CT scan results, and focal neurological signs.

\section{RESULTS}

Statistical analysis of the comparison of pre- and postguidelines figures was performed using Fisher Exact Probablitiy Tests (SPSS V11).

The number of head injured patients attending the department increased from 788 in November 1999 to 818 in May 2001 (table 1).

In November 1999, there were 575/718 (80\%) discharges to home from A\&E and 566/763 (74\%) in May 2001. Table 2

Table 1 Patients discharged from the A\&E department

\begin{tabular}{|c|c|c|c|}
\hline & 1999 & 2001 & p Value \\
\hline Number of attendances & 788 & 819 & \\
\hline Male patients & 575 (73\%) & $566(68 \%)$ & 0.04 \\
\hline No. of discharged patients & 645 (82\%) & $622(76 \%)$ & - \\
\hline $\begin{array}{l}\text { No. of discharges who had a } \\
\text { documented pupil check }\end{array}$ & $473(82 \%)$ & $458(81 \%)$ & 0.59 \\
\hline $\begin{array}{l}\text { No. of discharges who had a } \\
\text { documented CNS exam }\end{array}$ & $464(81 \%)$ & $429(76 \%)$ & 0.052 \\
\hline $\begin{array}{l}\text { No. of discharges who had a } \\
\text { documented GCS }\end{array}$ & $549(95 \%)$ & $555(98 \%)$ & 0.018 \\
\hline $\begin{array}{l}\text { No. of discharges who had a } \\
\text { SIGN indication for SXR }\end{array}$ & $223(40 \%)$ & $171(30 \%)$ & 0.003 \\
\hline $\begin{array}{l}\text { No. of discharges who had a } \\
\text { SIGN indicated SXR }\end{array}$ & $\begin{array}{l}168 / 223 \\
(75 \%)\end{array}$ & $\begin{array}{l}123 / 171 \\
(72 \%)\end{array}$ & 0.49 \\
\hline $\begin{array}{l}\text { No. of discharges who had a } \\
\text { SIGN indication for CT }\end{array}$ & $11(2 \%)$ & $11(2 \%)$ & 1.00 \\
\hline $\begin{array}{l}\text { No. of discharges who had a } \\
\text { SIGN indicated CT }\end{array}$ & $4 / 11(36 \%)$ & $7 / 11(64 \%)$ & 0.39 \\
\hline $\begin{array}{l}\text { No. of discharges fulfilling SIGI } \\
\text { 'safe discharge' criteria }\end{array}$ & V329 (57\%) & $251(44 \%)$ & $<0.001$ \\
\hline
\end{tabular}

CNS, central nervous system; CT, computed tomography; GCS, Glasgow Coma Scale; SIGN, Scottish Intercollegiate Guidelines Network; SXR, skull $x$ ray.
Table 2 Patients admitted to a ward from the A\&E department

\begin{tabular}{|c|c|c|c|}
\hline & 1999 & 2001 & p Value \\
\hline \multicolumn{4}{|c|}{$\begin{array}{l}\text { No. of admitted patients } 143 \quad 197 \\
\text { No. of patients with a } 139 / 149(93 \%) 191 / 208(92 \%) 0.69 \\
\text { SIGN indication to } \\
\text { admission }\end{array}$} \\
\hline $\begin{array}{l}\text { No. documented reason } \\
\text { for admission }\end{array}$ & $4 / 569(1 \%)$ & $6 / 555(1 \%)$ & 0.54 \\
\hline \multicolumn{4}{|c|}{$\begin{array}{l}\text { documented pupil check } \\
\text { in } A \& E\end{array}$} \\
\hline $\begin{array}{l}\text { No. who had a } \\
\text { documented CNS exam } \\
\text { in A\&E }\end{array}$ & $125(87 \%)$ & $173(88 \%)$ & 1.00 \\
\hline $\begin{array}{l}\text { No. who had a } \\
\text { documented GCS in } \\
\text { A\&E }\end{array}$ & $142(99 \%)$ & $194(98 \%)$ & 0.64 \\
\hline $\begin{array}{l}\text { No. who had a SIGN } \\
\text { indication for SXR }\end{array}$ & $131(92 \%)$ & $168(85 \%)$ & 0.09 \\
\hline $\begin{array}{l}\text { No. who had a SIGN } \\
\text { indicated SXR }\end{array}$ & $120 / 131$ (92\% & $133 / 168179 \%$ & 0.003 \\
\hline $\begin{array}{l}\text { No. who had a SIGN } \\
\text { indication for } \mathrm{CT}\end{array}$ & $23(16 \%)$ & $29(15 \%)$ & 0.76 \\
\hline $\begin{array}{l}\text { No. who had a SIGN } \\
\text { indicated CT }\end{array}$ & $16 / 23(70 \%)$ & $23 / 29(79 \%)$ & 0.52 \\
\hline No. with a positive scan & $10 / 19$ (53\%) & $8 / 28(29 \%)$ & 0.13 \\
\hline \multicolumn{4}{|c|}{$\begin{array}{l}\text { CNS, central nervous system; CT, computed tomography; GCS, Glasgon } \\
\text { Coma Scale; SIGN, Scottish Intercollegiate Guidelines Network; SXR, } \\
\text { skull } x \text { ray. }\end{array}$} \\
\hline
\end{tabular}

shows that a significantly lower proportion of patients had documented SIGN reasons for admission in November 1999 compared with May 2001. Similarly, a higher number of patients were admitted in period 2. Of patients with SIGN listed reasons for admission, most were admitted in both periods.

Compared to pre-implementation practices, a significantly higher proportion of post-guideline patients were documented as GCS 15/15 on discharge or no longer having admission criteria. Neither the rates of documenting pupil checks nor central nervous system examination changed significantly, and fewer patients were noted as receiving head injury advice cards or being discharged to suitable supervision. This result led to a significant reduction in the overall proportion of fully SIGN compliant discharges post-guidelines.

Altogether, 70/788 (9\%) patients who attended in period 1 took self discharge compared with $56 / 819(7 \%)$ in period 2 $(\mathrm{p}=0.14)$. These patients were not considered further. Of the remaining patients, excluding deaths in A\&E, 143 of the 718 patients who attended in period 1 were admitted compared with 197 of the 763 patients in period 2 (table 2).

The rate of skull $x$ ray (SXR) examination, when indicated, did not change significantly (tables 1 and 2). There was a significant post-implementation decrease in skull radiography in patients subsequently discharged, although the decrease amongst patients who had a SIGN listed reason for SXR was not significant. Of the 575 discharged patients in period 1, $223(39 \%)$ had SIGN indications for a SXR: of these, $168(75 \%)$ had SXR performed. CT scans on patients who were discharged from A\&E were rare patients (12/114l $(1.1 \%))$ and showed no significant change post-guidelines.

There was a significant post-implementation decrease in SXR amongst admitted patients, matched by a significant decrease in those who had a SIGN reason for SXR but who were not $x$ rayed, and there was an insignificant difference between the two periods in the proportion of patients with skull fractures confirmed by SXR. All eleven patients who had a skull fracture identified on $x$ ray subsequently underwent a CT scan.

There was no significant change in the overall proportion of admitted patients who had a CT scan (table 2). Altogether, 
$15-16 \%$ of admitted patients had SIGN reasons for a CT scan, and approximately three quarters of these were scanned. The proportion of negative scans increased from $47 \%$ to $71 \%$ $(\mathrm{p}=0.13)$. The most frequently documented reasons for CT scanning were GCS $<12$, or evidence of skull fracture from SXR or clinically. Of patients with a documented reason for CT scanning, those with a GCS $<12$ were least likely to be scanned.

Table 3 shows the destinations of admitted patients. Ward management data were collected for patients who went to surgical, orthopaedic, short stay, or high dependancy unit wards, intensive trauma unit, or theatre. Data were not collected for patients who went to medical wards (including maternity, geriatrics, plastics, ophthalmology, maxillo-facial surgery, ear, nose, and throat, psychiatry) or surgical intensive care unit. Patients transferred to the WGH Neurosurgical Unit are considered later. There was no significant difference in the proportion of patients who had a documented assessment on admission to the ward postguidelines (table 4). There was a small post-guidelines drop in the percentage of patients who had complete reviews. Documented safe discharge compliance from the wards (table 5) increased from 38/76 (50\%) patients pre-implementation to $99 / 112(88 \%)$ patients post-implementation $(\mathrm{p}<0.001$; table 5). Altogether, 3/109 (3\%) of admitted patients (excluding medical, and so forth) deteriorated in 1999 compared with $0 / 157(0 \%)$ in $2001(p=0.07)$. None required neurosurgical intervention.

Altogether, 11/143 pre-implementation patients and 9/197 post-implementation patients were transferred to the WGH Neurosurgical Unit. There was no significant change in transfer rates, either directly from A\&E or later. There were nine discharges home and two self discharges from A\&E who had documented referral/transfer reasons (seven pre-implementation, four post-implementation). Most had base of skull fracture signs. Only two discharges were referred to neurosurgery before discharge.

\section{DISCUSSION}

This audit examines whether practice changed post SIGN guidelines inception in a busy A\&E department. In terms of patient demographic and aetiology, our patient group matches other studies from Scotland and the UK, ${ }^{2}{ }^{14}$ although assault as a mechanism of injury was slightly more common in our study group. This was also found by Strang et $a l^{15}$ and Swann et al ${ }^{16}$ who found proportionally more admissions in outlying hospitals related to road traffic accidents.

For admission criteria, the SIGN guidelines are followed and fewer patients without a SIGN indication for admission were admitted post-implementation. For admitted patients, a proforma exists for admission documentation; when used, documentation is accurate and comprehensive (GCS

Table 3 Post A\&E destinations of admitted patients

\begin{tabular}{|c|c|c|}
\hline & 1999 & 2001 \\
\hline Number of patients & 143 & 197 \\
\hline $\begin{array}{l}\text { Ward: surgical, orthopaedic } \\
\text { short stay, or HDU }\end{array}$ & $108(76 \%)$ & $155(79 \%)$ \\
\hline Ward: medical & $24(17 \%)$ & $19(10 \%)$ \\
\hline Intensive trauma unit & $2(1 \%)$ & \\
\hline Theatre & $1(1 \%)$ & \\
\hline Other hospital* & $12(6 \%)$ & \\
\hline \multicolumn{3}{|l|}{ Neurosurgery } \\
\hline Direct transfer to Neuro & $10(7 \%)$ & $9(5 \%)$ \\
\hline Late transfer to Neuro & $1(1 \%)$ & $0(0 \%)$ \\
\hline Combined & $11(8 \%)$ & $9(5 \%)$ \\
\hline
\end{tabular}

\section{Table 4 Ward management}

\begin{tabular}{|c|c|c|c|}
\hline & 1999 & 2001 & p Value \\
\hline $\begin{array}{l}\text { Number of patients } \\
\text { admitted to RIE ward }\end{array}$ & 109 & 157 & \\
\hline Assessed on admission & $97(89 \%)$ & $133(85 \%)$ & 0.36 \\
\hline $\begin{array}{l}\text { Self discharged within } 24 \\
\text { hours }\end{array}$ & $22(20 \%)$ & $18(11 \%)$ & 0.056 \\
\hline $\begin{array}{l}\text { Documented review within } \\
24 \text { hours* } \\
\text { Complete review within } \\
24 \text { hours }\end{array}$ & 81 (93\%) & $120(86 \%)$ & 0.13 \\
\hline All admissions & $6 / 87(7 \%)$ & \multirow{2}{*}{\multicolumn{2}{|c|}{$\begin{array}{l}39 / 139(28 \%)<0.001 \\
39 / 120(32 \%)<0.001\end{array}$}} \\
\hline $\begin{array}{l}\text { If any review } \\
\text { undertaken }\end{array}$ & $6 / 81(7 \%)$ & & \\
\hline $\begin{array}{l}\text { No fulfilling "safe } \\
\text { discharge" from ward } †\end{array}$ & $38 / 76(50 \%)$ & \multicolumn{2}{|c|}{$99 / 112(88 \%)<0.001$} \\
\hline \multicolumn{4}{|c|}{$\begin{array}{l}\text { *Excludes patients who self discharged within } 24 \text { hours; texcludes self } \\
\text { discharges, deaths, and transfers to other wards/hospitals and patients } \\
\text { who remained in hospital for more than two days. RIE, Royal Infirmary of } \\
\text { Edinburgh. }\end{array}$} \\
\hline
\end{tabular}

Table 5 Safe discharge from wards

\begin{tabular}{|c|c|c|c|}
\hline & 1999 & 2001 & p Value \\
\hline $\begin{array}{l}\text { Number of patients } \\
\text { Patient assessed } \\
\text { Eating and drinking } \\
\text { Neuro signs resolved } \\
\text { Mobile } \\
\text { Results reviewed } \\
\text { Head injury advice card } \\
\text { Safe discharge (all of } \\
\text { above) }\end{array}$ & $\begin{array}{l}76 \\
65(86 \%) \\
60(79 \%) \\
64(84 \%) \\
66(87 \%) \\
59(78 \%) \\
d 48(63 \%) \\
38(50 \%)\end{array}$ & $\begin{array}{l}112 \\
102(91 \%) \\
103(92 \%) \\
100(89 \%) \\
102(91 \%) \\
102(91 \%) \\
99(88 \%) \\
99(88 \%)\end{array}$ & $\begin{array}{l}0.25 \\
0.015 \\
0.37 \\
0.47 \\
0.012 \\
<0.001 \\
<0.001\end{array}$ \\
\hline
\end{tabular}

documentation: $95 \%$ in period 1 and $98 \%$ in period 2). Despite guidelines, patients were admitted who satisfied criteria for discharge home from A\&E. In a previous audit, Brown et $a l^{2}$ found that access to hospital beds is a major determinant of management in patients presenting with minor head injury, and may be more influential than clinical findings. For admitted patients, there was no significant change in the proportion of patients with documented pupil or CNS examinations in A\&E, although there was an improvement in GCS documentation. Of the five patients who were not admitted despite a SIGN indication, one represented and was managed conservatively.

Although there are a number of published guidelines on the early management of the head injured patient, with a few exceptions there is a consensus on which individuals should attend and be admitted to hospital. However, imaging of the head injured patient remains a controversial issue. SXRs continue to be performed in patients without SIGN indications. This is related to the grade and clinical experience of the doctor requesting the investigation, but may also represent pressure from the patient to have the investigation performed. A previous study by McNally et $a l^{17}$ assessed patients' reactions to not having skull radiography performed, and demonstrated that, of 705 patients questioned, 51\% said they expected a SXR to be performed, and of these $63 \%$ had left the department disappointed.

It appears that our use of CT scanning is largely SIGN compliant. The most likely indication for scanning is a GCS $<12$; but it is this very group of patients who, in this audit, are least likely to have been scanned. Patients with GCS $<12$ are not a homogenous group, having a wide spectrum of aetiologies; because of this, Teasdale and 
Jennett suggest that the GCS score must be used in the clinical context of the patient. ${ }^{18}$ Furthermore the SIGN guidelines are not specific in some indications-for example, what exactly is "persistent vomiting"? A significant proportion of head injured patients have taken alcohol, which again makes interpretation of the GCS more difficult. Illicit drug use will also affect the GCS; clinically both alcohol and drugs must be taken into consideration in deciding the patient's further investigations regardless of their GCS.

In terms of ward discharges, an interesting finding is the improvement in compliance from $50 \%$ to $88 \%$. It is not known whether this has been led by surgeons, nurses, or A\&E staff; however, most individuals are suitable for discharge by the nursing staff if they fulfil the SIGN criteria. Post-publication the guidelines were distributed on the wards and made available to all staff looking after head injured patients. This appears to be one area where specific instruction has resulted in an increase in compliance.

For patients transferred to the WGH Neurosurgery Unit, there has been little change in practice. Most patients with SIGN indications for transfer who were not transferred had signs of a skull base fracture. Mendelow et al concluded that the role of CT in detecting intracranial haematomas was well established, but it did not affect the dilemma of deciding which patients were admitted to a surgical ward or should be transferred to a neurosurgical unit. It is assumed that if more patients were promptly transferred to neurosurgical centres, there would be a reduction in mortality and morbidity from intracranial haematoma. In our study there is no evidence of undue delay leading to adverse outcome. ${ }^{19}$

One of the difficulties inherent in this kind of study relates to adequacy of documentation. In a busy A\&E department, especially on weekend nights when a substantial proportion of our head injured patients attend, it is not always possible to make comprehensive documentation the main priority. From the point of view of safe discharge from A\&E, it may be that "suitable supervision" is documented poorly in younger patients accompanied by a responsible individual. In the elderly, however, more consideration is required as to whether the patient lives alone or has family support. In terms of discharge advice, head injury advice cards may be issued by either an A\&E doctor or nurse, and this is not always documented in the notes.

Another point of consideration is that the audit proforma notes the information recorded in the A\&E document as recorded by the assessing doctor and does not refer to the nursing triage entry. In some instances, therefore, the doctor may not duplicate information already recorded in the nursing entry and this will have been overlooked in the proforma. Despite this, some parameters are recorded more consistently than others-the results show that the vast majority of patients have documentation of their GCS and any evidence of alcohol; however, our recording of any amnesia is poorer and inconsistent. This is presumably a reflection of the established importance of the GCS in determining the severity of the head injury as compared with the presence of amnesia, which correlates well with subsequent disability. The latter may therefore be considered to be of secondary importance in initial assessment. This study has shown that we should address this issue in the training of junior doctors who assess these patients.

\section{CONCLUSIONS}

Overall SIGN guidelines have not made a significant difference to the investigation and management of head injured patients in this large teaching hospital, except in the frequency of CT scanning and "safe" ward discharges. In the post-guidelines implementation phase, aspects of poor compliance relate principally to the documentation and provision of formal head injury advice and ensuring adequate supervision post discharge. From this viewpoint, systems are required that routinely monitor guideline implementation and compliance.

\section{Authors' affiliations \\ J Kerr, C E Robertson, Accident \& Emergency Department, Royal Infirmary of Edinburgh \\ R Smith, S Gray, D Beard, Scottish Trauma Audit Group}

Competing interests: none declared

The Corresponding Author has the right to grant on behalf of all authors and does grant on behalf of all authors, an exclusive licence (or non exclusive for government employees) on a worldwide basis to the BMJ Publishing Group Ltd to permit this article (if accepted) to be published in EMJ and any other BMJPGL products and sublicences such use and exploit all subsidiary rights, as set out in our licence (http:// emj.bmijournals.com/misc/ifora/licenceform.shtml).

\section{REFERENCES}

1 American College of Surgeons. Advanced Trauma Life Support, Student Course Manual. American College of Surgeons, 10-11. 1997.

2 Brown SR, Raine C, Robertson CE, et al. Management of minor head injuries in the accident and emergency department: the effect of an observation ward. $J$ Accid Emerg Med 1994;1 1(1): 144-8.

3 Jennett B. Epidemiology of head injury. J Neur Neurosurg Psych 1996;60:362-9.

4 Scottish Intercollegiate Guidelines Network. Early Management of Patients with a Head Injury. A National Clinical Guideline. August 2000;46.

5 Mendelow AD, Campbell DA, Jeffrey RR, et al. Admission after mild head injury: benefits and costs. BMJ 1982;285:1530-2.

6 Thornhill S, Teasdale GM, Murray GD, et al. Disability in young people and adults one year after head injury: prospective cohort study. BMJ 2000;320:1631-5.

7 Roy CW, Pentland B, Miller, JD. The causes and consequences of minor head injury in the elderly. Injury 1986;17:220-3.

8 The management of acute head injury: seminar papers. London: DHSS 1983.

9 Guidelines for initial management after head injury in adults - suggestions from a group of neurosurgeons. BMJ 1984;288:983-5.

10 Royal College of Surgeons of England. Report of the Working Party on the Management of Patients with Head Injuries. London: The College, 1999.

11 Steill IG, Wells GA, Vandemheen K, et al. The Canadian CT head rule for patients with minor head injury. Lancet 2001;357:1391-6.

12 National Institute for Clinical Excellence. Triage, assessment, investigation and early management of head injury in infants, children and adults. London: NICE, June, 2003.

13 Arienta C, Caroli M, Balbi S. Management of head-injured patients in the Emergency Department: A practical protocol. Surg Neurol 1997;48:213-9.

14 Miller JD, Jones PA. The work of a regional head injury service. Lancet 1985:1141-4.

15 Strang I, MacMillan R, Jennett B. Head injuries in accident and emergency departments at Scottish hospitals. Injury 1978;10:154-9.

16 Swann IJ, MacMillan R, Strang I. Head injuries at an inner city accident and emergency department. Injury $1981 ; 12: 274-8$

17 McNally $E$, de Lacey $G$, Lovell $P$, et al. The effect on patients of non-referral for skull radiography following mild head injury. Injury 1996;27:429-31.

18 Teasdale G, Jennett B. Assessment of coma and impaired consciousness. A practical scale. Lancet 1974:81-4.

19 Dunn LT, Fitzpatrick MO, Beard D, et al. Patients with a head injury who "talk and die" in the 1990's. J Trauma 2003;54(3):497-502. 


\section{APPENDIX 1}

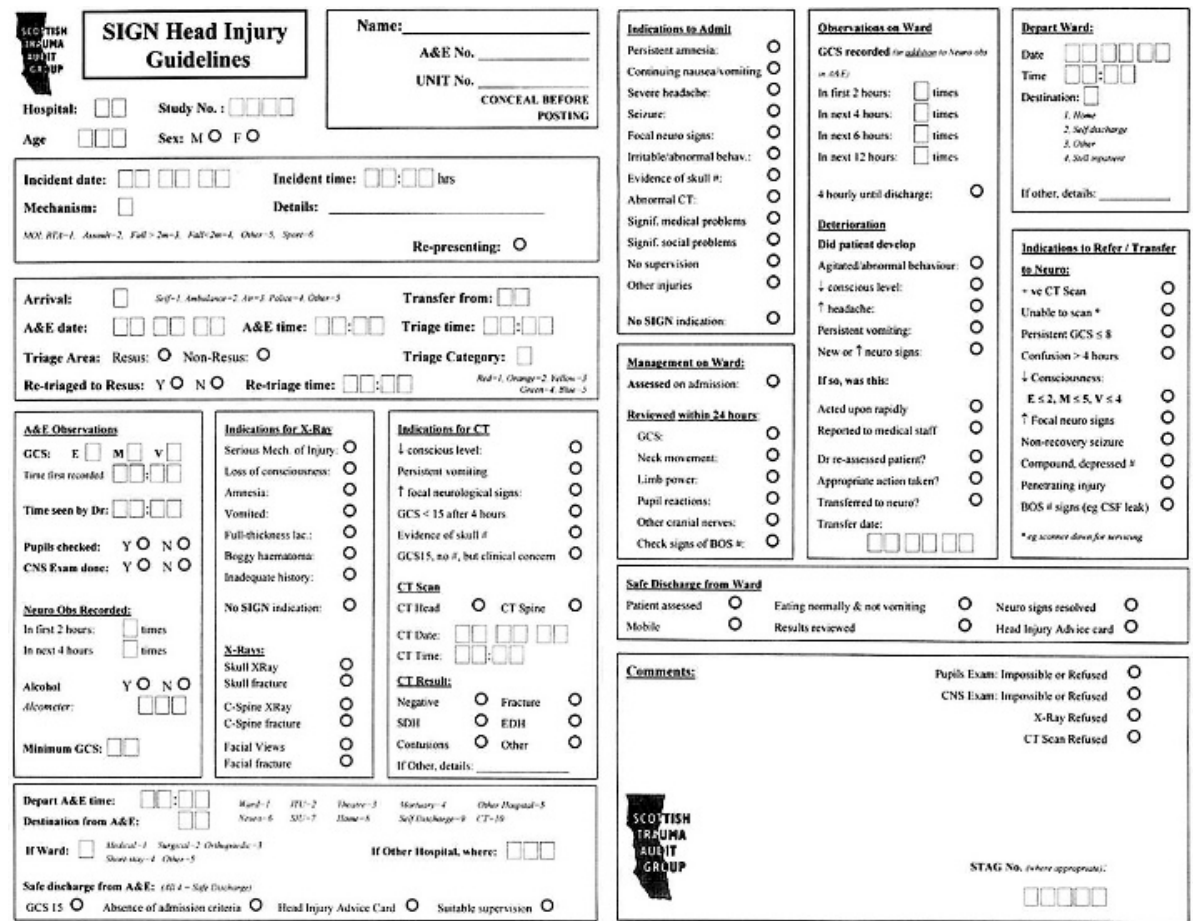

Figure 1 For each patient attending the A\&E department with a head injury, a proforma was completed

\section{bmjupdates+}

bmiupdates+ is a unique and free alerting service, designed to keep you up to date with the medical literature that is truly important to your practice.

bmjupdates+ will alert you to important new research and will provide you with the best new evidence concerning important advances in health care, tailored to your medical interests and time demands.

Where does the information come from?

bmjupdates+ applies an expert critical appraisal filter to over 100 top medical journals A panel of over 2000 physicians find the few 'must read' studies for each area of clinical interest

Sign up to receive your tailored email alerts, searching access and more...

www.bmjupdates.com 